\title{
Interactions of Hydrogen Isotopes and Oxides with Metal Tubes
}

\section{$8^{\text {th }}$ International Conference on Tritium Science and Technology}

\author{
Glen R. Longhurst \\ James Cleaver
}

\author{
August 2008
}

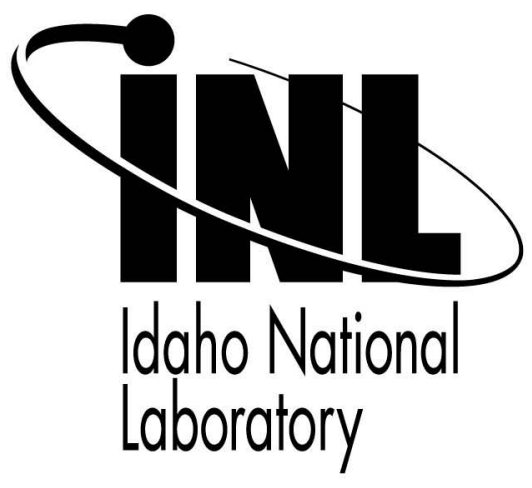

This is a preprint of a paper intended for publication in a journal or proceedings. Since changes may be made before publication, this preprint should not be cited or reproduced without permission of the author. This document was prepared as an account of work sponsored by an agency of the United States Government. Neither the United States Government nor any agency thereof, or any of their employees, makes any warranty, expressed or implied, or assumes any legal liability or responsibility for any third party's use, or the results of such use, of any information, apparatus, product or process disclosed in this report, or represents that its use by such third party would not infringe privately owned rights. The views expressed in this paper are not necessarily those of the United States Government or the sponsoring agency. 


\title{
INTERACTIONS OF HYDROGEN ISOTOPES AND OXIDES WITH METAL TUBES
}

\author{
Glen R. Longhurst ${ }^{\mathrm{a}}$ and James Cleaver ${ }^{\mathrm{b}}$ \\ Idaho National Laboratory,P.O. Box 1625, Idaho Falls, Idaho,83415-3860, Glen.Longhurst@inl.gov \\ ${ }^{b}$ Idaho State University, 921 South ${ }^{\text {th }}$ Avenue, Pocatello, Idaho, 83201
}

Understanding and accounting for interaction of hydrogen isotopes and their oxides with metal surfaces is important for persons working with tritium systems. Reported data from several investigators have shown that the processes of oxidation, adsorption, absorption, and permeation are all coupled and interactive. A computer model has been developed for predicting the interaction of hydrogen isotopes and their corresponding oxides in a flowing carrier gas stream with the walls of a metallic tube, particularly at low hydrogen concentrations. An experiment has been constructed to validate the predictive model. Predictions from modeling lead to unexpected experiment results.

\section{OVERVIEW}

Understanding and accounting for interaction of hydrogen isotopes and their oxides with metal surfaces is important for persons working with tritium systems. In high inventory systems, such as fusion reactors or production facilities, it has safety implications. In small inventory experiments, it is essential to successful observation and interpretation of experimental data. Reported data from several investigators have shown that the processes of oxidation, adsorption, absorption, and permeation are all coupled and interactive.

Stainless steel surfaces have been found to be effectively modeled as having 2 kinds of associated water. One, termed "bound" or chemisorbed water, is in relatively permanent residence and is independent of the partial pressures of the vapors above it. Sensitive to temperature, bound water is also subject to isotopic exchange with the other type of adsorbed water, termed "non-bound" or physisorbed, which is volatile or releasable. Copper seems to have no bound water, only non-bound adsorbed water. The supposition that exchange of bound water takes place only with non-bound water, not with gas-phase water, is consistent with observations. The isotopic ratio in the bound water is assumed to follow that in the non-bound water because of exchange of molecules from the bound inventory to the non-bound inventory and vice versa. That exchange does not appear to be instantaneous, however.

\section{PREVIOUS EXPERIMENTS}

Studies by Nishikawa et al., ${ }^{1}$ Shiraishi et al., ${ }^{2}$ and Longhurst $^{3}$ illustrate various aspects of the complex interactions taking place on metal surfaces.

\section{II.A. Nishikawa}

The experiments of Nishikawa et al. ${ }^{1}$ used mixtures of HT, HTO, and $\mathrm{H}_{2}$ in $\mathrm{N}_{2}$ with $\mathrm{H} / \mathrm{T}$ ratios up to several tens of thousands to conduct experiments on isotopic exchange of elemental and oxidized hydrogen isotopes (H: protium, D: deuterium, T: tritium) with stainless steel, copper and quartz.. They observed an inventory of water on the surface of stainless steel that isotopically exchanged with water entering the system as a vapor but which did not readily desorb from the surface into dry gas. In particular, they found that after exposure to 925$\mathrm{MBq} / \mathrm{m}^{3} \mathrm{HTO}$, when flushing their system with $\mathrm{H}_{2} \mathrm{O}$ laden $\left(5200 \mathrm{~cm}^{3} / \mathrm{m}^{3}\right)$ nitrogen immediately after flushing with dry nitrogen alone, tritium desorption from 304 stainless steel at $15^{\circ} \mathrm{C}$ was about 1.8 times as great as when the dry nitrogen was used alone. Repeating the sequence of gas flushes 24 hours later, they saw the ratio of tritium release in moist gas to release in dry gas immediately prior increased to 4 , though the total amount removed was only $3 \%$ of the initial removal. Then, 48 hours after the initial trial, dry nitrogen would not remove any more tritium, and only $0.6 \%$ of the initial tritium release was removed by the $\mathrm{H} 2 \mathrm{O}$-laden gas. This latent release after waiting a day was not seen on copper or quartz.

The removal of only part of the adsorbed tritium by dry gas and more with moist gas is evidence for the two kinds of surface water. The generation of additional removable tritium from stainless steel after waiting one or two days was attributed by Nishikawa et al. ${ }^{1}$ to difficulty in adsorbed water moving through a surface layer of $\mathrm{Fe}_{3} \mathrm{O}_{4}$ found on the surface. While that may be, it seems also possible that tritium was coming out of solution in the metal and forming water.

Nishikawa et al. ${ }^{1}$ found the total amount of HTO adsorbed in both forms on the surface to be independent 
of water vapor pressure above it but to be proportional to temperature. Their water saturation values, $w_{T}\left(\mathrm{~mole} / \mathrm{m}^{2}\right)$ for 304 stainless steel and copper data are fit well by

$$
\begin{gathered}
w_{T S S}=0.009 \exp (-0.006 T) \\
w_{T C u}=0.0217 \exp (-0.0122 T)
\end{gathered}
$$

respectively, though Nishikawa et al. ${ }^{1}$ found different expressions. They found the mass transfer coefficient, $K_{f}(\mathrm{~m} / \mathrm{s})$, from the vapor to the adsorbed phases for all materials to be

$$
K_{f}=5.4 \times 10^{-5} \exp \left(-\frac{4180}{R T}\right)
$$

where $\mathrm{R}$ is the universal gas constant and $\mathrm{T}$ is temperature in kelvin.

\section{II.B. Shiraishi Data}

Shiraishi et al. ${ }^{2}$ measured release of ordinary $\mathrm{H}_{2} \mathrm{O}$ from stainless steel, copper, and aluminum surfaces flushed with dry argon using a hygrometer to determine water content. They found that for copper and aluminum, the inventory, $q\left(\mathrm{~mole} / \mathrm{m}^{2}\right)$ of non-bound water was sensitive to both temperature and pressure according to

$$
q=A P^{B} \exp \left(\frac{E_{w}}{R T}\right)
$$

where $\mathrm{P}$ is the partial pressure $(\mathrm{Pa})$ of the water vapor in the gas. Their data for stainless steel were refit to include temperature dependence. The parameters A, B, and Ew are listed in Table 1 for stainless steel, copper, and aluminum. Their mass transfer coefficient was

$$
K_{f}=1.49 \times 10^{-3} \exp \left(-\frac{2420}{R T}\right)
$$

TABLE I. Water saturation parameters for experiments of Shiraishi et al. ${ }^{2}$

\begin{tabular}{lccc}
\hline \multicolumn{1}{c}{ Material } & $\mathbf{A}\left(\mathbf{m o l e} / \mathbf{m}^{2}\right)$ & $\mathbf{B}$ & $\begin{array}{c}\mathbf{E}_{\mathbf{w}} \\
(\mathbf{J} / \mathbf{m o l e})\end{array}$ \\
\hline 304 stainless steel & $1.4 \times 10^{-6}$ & 0.75 & 2,910 \\
Copper & $3.19 \times 10^{-8}$ & 0.75 & 12,600 \\
Aluminum & $1.08 \times 10^{-6}$ & 0.50 & 8,500 \\
\hline
\end{tabular}

\section{II.C. Longhurst Data}

Experiments performed by Longhurst ${ }^{3}$ demonstrated that tritium from HTO effectively permeates stainless steel, essentially as if it was elemental gas. In those experiments, HT in He was admitted to a heated permeation column of stainless steel. The rate at which it oxidized was determined by periodically applying liquid nitrogen $\left(\mathrm{LN}_{2}\right)$ traps that would remove HTO. It was thus possible to determine from ion chamber counts the amount of tritium that was condensable and assumed oxidized.

There was an observed conversion of elemental tritium (HT) to HTO on the upstream side of the permeation wall with an associated partial loss of tritium from the gas stream as the HTO adsorbed on surfaces. When, with the cold trap active, the elemental gas was removed leaving only the frozen HTO which was subsequently melted and vaporized in new pure $\mathrm{He}$, the permeation continued as if an equivalent partial pressure of elemental gas was driving it. On the downstream side, the permeating tritium was again found to be mostly in the oxide form. The rate of conversion from the elemental gas in the system followed the equation

$$
\frac{d c_{H T O}}{d t}=-\frac{d c_{H T}}{d t}=1.987 \frac{S}{V} \exp \left(-\frac{62,844}{R T}\right) c_{H T}
$$

where $c_{x}$ (x: HTO or HT) are concentrations and $S / V$ is the surface to volume ratio $\left(\mathrm{m}^{-1}\right)$ of the system. Diffusion of tritium through the 316 stainless steel tube between upstream and downstream flow circuits could be described well with classical diffusivity and Sieverts' law solubility values. ${ }^{4}$

\section{RESULTING MODEL}

A numerical model was developed that includes surface processes of adsorption and desorption of nonbound water on the surface from and to vapor over it, exchange between bound and non-bound surface water, dissociation of elemental gas and decomposition/ recombination of non-bound surface water molecules into/from surface-dissolved atomic species, diffusion of atom species through the tube wall, and convection and diffusion along the length of a tube. Surface processes are illustrated in Fig. 1. There only $\mathrm{H}$ is shown, but the model also accommodates a second species ( $\mathrm{D}$ or $\mathrm{T}$ ) and the heteronuclear species, such as HD and HDO, as well.

While several parameters remain to be quantified and will depend on surface conditions, the model gives excellent reproductions of the data presented by Shiraishi et al. $^{2}$, and reasonably good agreement with the Nishikawa et al. ${ }^{1}$ and Longhurst ${ }^{3}$ data. As an example, Fig. 2 compares the model results with experimental data for stainless steel of Shiraishi et al. ${ }^{2} \mathrm{H}_{2} \mathrm{O}$ flowed through a 10-m length of 4-mm internal diameter 304 stainless steel tube at $283 \mathrm{~K}$ for one hour followed by dry $\mathrm{N}_{2}$ alone for another 90 minutes. Then the temperature 


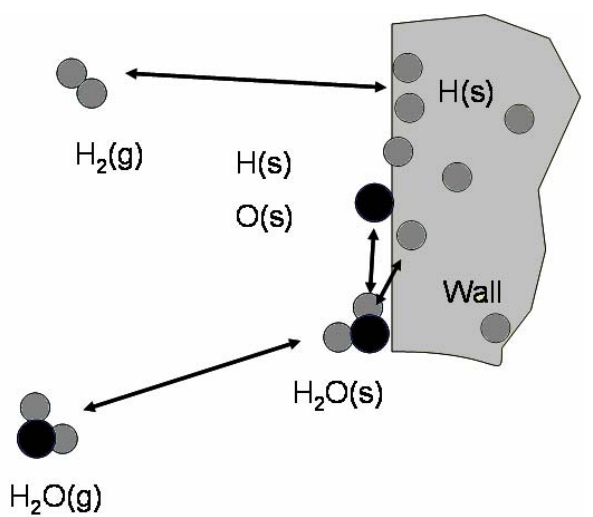

Fig. 1. Processes considered in analyzing non-bound water adsorption and solution at the walls.

$$
\text { ○ } \quad \text { Shiraishi Figure } 2-\text { Model } \cdots \cdots \text {... Temperature }
$$

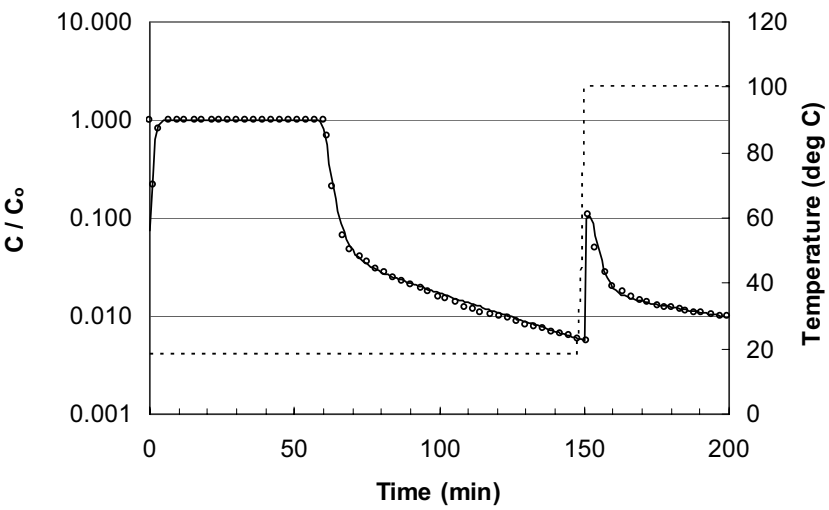

Fig. 2. Comparison of model results with data from Shiraishi et al. ${ }^{2}$ was raised to $373 \mathrm{~K}$, and observations were taken for another 50 minutes. Modeling results (the ratio of $\mathrm{H}_{2} \mathrm{O}$ concentration at the outlet, $c$, to initial concentration at the inlet, $c_{o}$, is shown in Fig. 2) showed that when the source flow stopped at 60 minutes, the initial water evolution rate was governed by release of non-bound water using a mass transfer coefficient close to that of Shiraishi et al. ${ }^{2}$, Eq. (5). From 70 minutes to 150 minutes, the tritium signal was vapor escaping from what was modeled as a small virtual leak also seen by the researchers. At 150 minutes, the temperature change resulted in a decrease in bound water with the resulting increase in non-bound water, which was then released to the gas stream.

\section{NEW EXPERIMENT}

Experimental data presently available do not address very low hydrogen atom concentrations and flow rates. Information to adequately quantify oxidation and other chemical processes under the flow and metal surface conditions of planned experiments is not yet available. As a means of further understanding processes at very low flow rates and hydrogen isotope concentrations, considering particularly conversion to and from oxides and uptake in tube walls, an experiment has been initiated at the Idaho National Laboratory in which specific parameters may be varied to explore interactions of hydrogen isotopes and their oxides with metal tubing. A schematic is shown in Fig. 3.

The carrier gas is ultra-high purity $\mathrm{N}_{2} . \mathrm{D}_{2}$ is supplied at a very low rate $\left(5.6 \times 10^{11}\right.$ molecules/s $)$ through the calibrated leak when called for. A metering valve in parallel with a $2.3-\mathrm{kPa}(1 / 3 \mathrm{psi})$ check valve allows passing a fraction of that $\mathrm{D}_{2}$ current through the experiment.

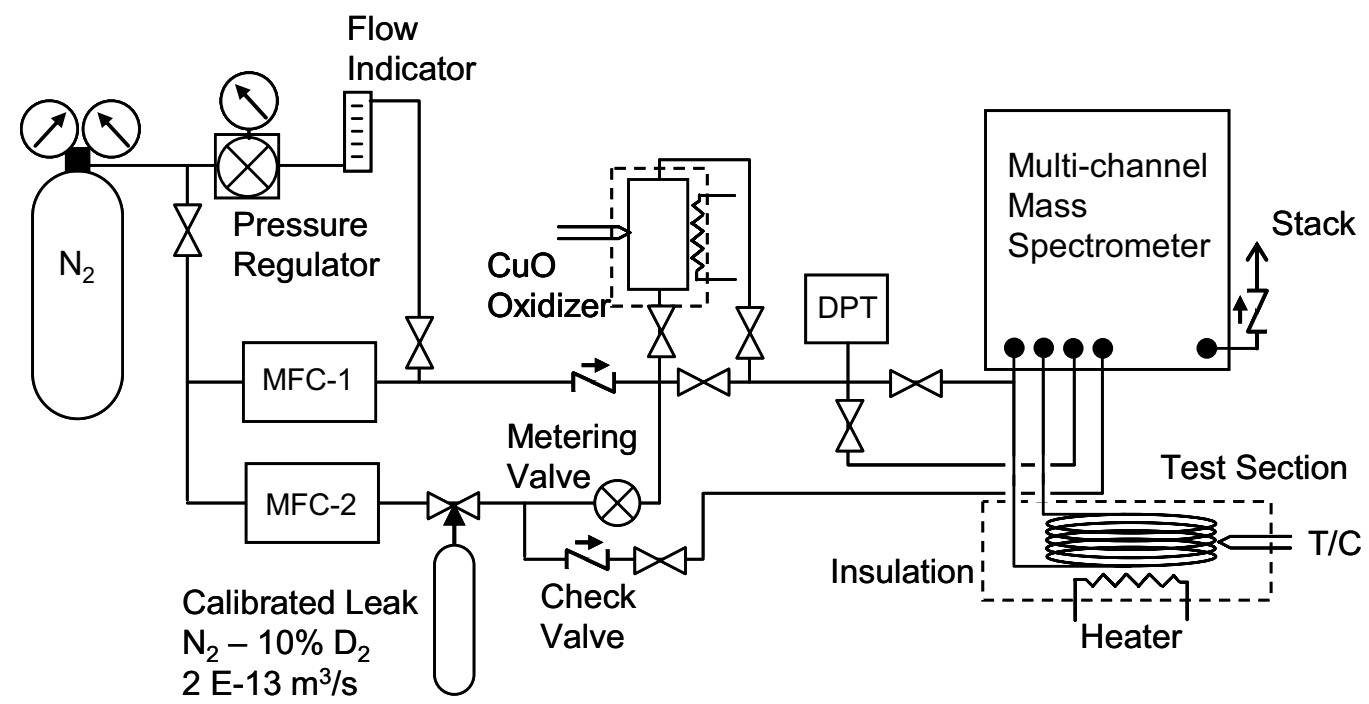

Fig. 3. Schematic of low-flow hydrogen transport experiment to be used in verifying the transport model developed. 
Mass flow controllers (MFCs) combine $\mathrm{D}_{2}$-bearing gas with pure $\mathrm{N}_{2}$ to achieve total gas flow rates from $2 \mathrm{x}$ $10^{-8}$ to $4.2 \times 10^{-7} \mathrm{~m}^{3} / \mathrm{s}$ and $\mathrm{D}_{2}$ concentrations from $5 \mathrm{~mm}^{3} / \mathrm{m}^{3}$ to $1.25 \mathrm{~cm}^{3} / \mathrm{m}^{3}$. Deuterium detection is by a multi-channel mass spectrometer, which is coaxed into sensitivities of order 10 to $100 \mathrm{~mm}^{3} / \mathrm{m}^{3}$. The test section is a $33-\mathrm{m}(100 \mathrm{ft})$ length of $3.1-\mathrm{mm}(1 / 8$-inch) 304 stainless steel or copper tubing, which may be heated to more than $150^{\circ} \mathrm{C}$. Lines other than the test section are mostly 6.2$\mathrm{mm}$ (1/4-inch) 304 stainless steel. To examine associated processes for $\mathrm{D}_{2} \mathrm{O}$, the entrance gas stream may be passed through a hot $\left(365^{\circ} \mathrm{C}\right) \mathrm{CuO}$ (oxidized $\mathrm{Cu}$ turnings) oxidizer bed. A pressure-regulated bypass of the MFCs allows much higher flow of the $\mathrm{N}_{2}$ alone for loop purging. A differential pressure transducer (DPT) provides pressure measurement at the upstream end of the test section. The MFCs and mass spectrometer are computercontrolled. Data recording is also computer based.

The experiment has been assembled and calibrated. Flow calibration used positive gas displacement methods. The mass spectrometer was calibrated using standard leaks and known gas mixtures. Control and data conversion algorithms have been developed.

The calculational model, in its present state of development, was used with estimated parameters to give results that may be seen in the experiment. Cases were modeled in which the total gas flow is $1.7 \mathrm{E}-7 \mathrm{~m}^{3} / \mathrm{s}$ with $\mathrm{D}_{2}$ at $100 \mathrm{~mm}^{3} / \mathrm{m}^{3}$ at an ambient temperature of $296 \mathrm{~K}$ through both 304 SS and copper. The prediction for deuterium concentration at the outlet of the tube as a fraction of the inlet atom concentration is shown in Fig. 4.

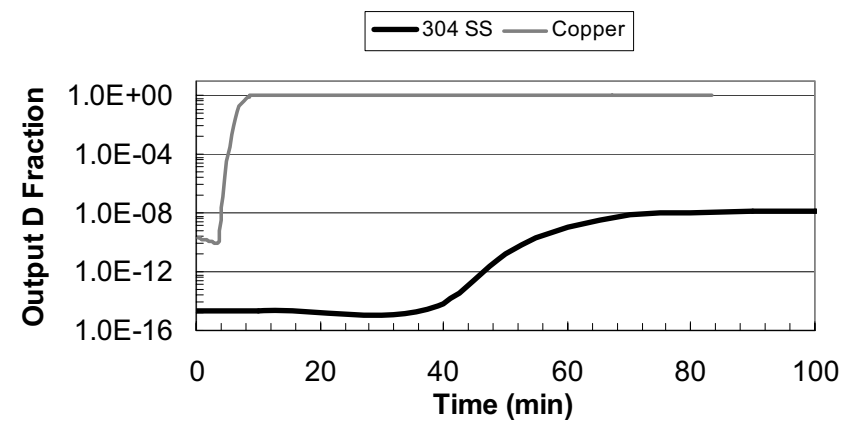

Fig. 4. Deuterium atom concentration in output stream.

For the copper, there is nothing surprising or unusual. The lag of about 5 minutes is simply the time it takes the gas to get through the system. For the stainless steel, however, a much different result was found. There is a delay in seeing anything at the outlet for about 50 minutes. This is much more than the time needed for the gas to travel from inlet to outlet.

The steady state value of $\mathrm{D}$ atom concentration in the outlet was calculated to be only $1.2 \times 10^{-8}$ times its concentration at the inlet. This would create a problem in observation and interpretation in the experiment. The explanation is that, for the condition modeled, as $\mathrm{D}_{2}$ moves down the tube, it becomes dissolved in the tube surface and diffuses to the outside. This is illustrated in Fig. 5, which shows logarithmic concentration profiles for $\mathrm{D}$ atoms in the tube wall at times of $10,30,80$, and 140 minutes for distances of $0.165,19.365$, and $32.85 \mathrm{~m}$ from the inlet. The longer breakthrough time is thus really a saturation time of $\mathrm{D}$ atom build-up in the tube wall. Notice that the curve shape in Fig. 4 is much more like a diffusion transient than a breakthrough.

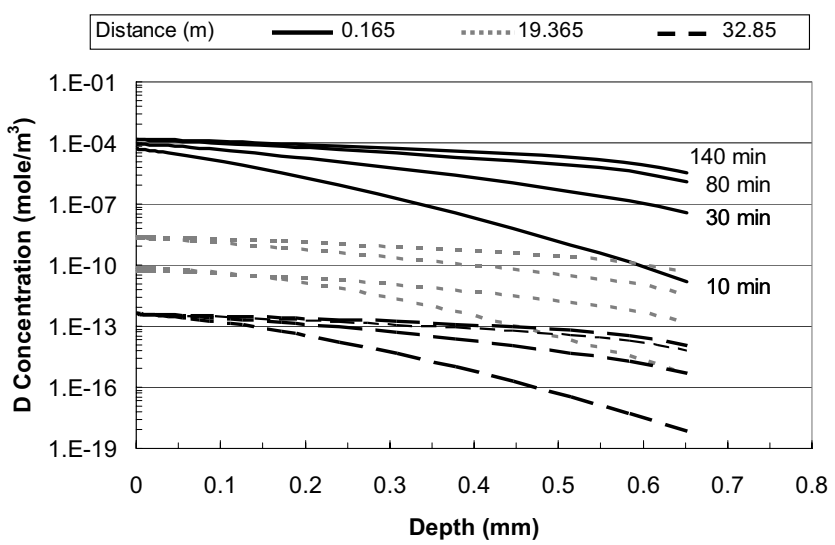

Fig. 5. Calculated D atom concentration profiles in the tube wall.

\section{CONCLUSION}

Experiments with hydrogen isotopes at low concentrations may give results that are not intuitive to researchers used to working at higher concentrations. Clearly, it will be important to understand processes involving these isotopes in sufficient detail to know what to look for in experiments of this kind.

\section{ACKNOWLEDGMENT}

Work performed for the U.S. Department of Energy, Deputy Administrator for Defense Programs under DOE Idaho Operations Office Contract DE-AC07-05ID14517.

\section{REFERENCES}

1. M. NISHIKAWA et al., "Tritium Mass Balance in the Piping System of a Fusion Reactor," Fus. Tech..21, 878 (1992).

2. T. SHIRAISHI et al., "Adsorption and Desorption Behavior of Tritiated Water on the Piping Materials," J. Nucl. Sci. Tech., 34, 687 (1997).

3. G. R. LONGHURST, "Tritiated Water Interaction with Stainless Steel," INL/EXT-07-12584, Idaho National Laboratory, Idaho Falls, Idaho (2007).

4. T. TANABE et al., "Hydrogen Transport in Stainless Steels," J. Nucl. Mater. 122 \& 123, 1568 (1984). 